\title{
Consideration regarding the reduction of pollutions emissions by increasing energy efficiency in ship operations
}

\author{
Lucian Mihail Dumitrache ${ }^{1}$, Nicolae Buzbuchi ${ }^{1}$, Cătălin Faităr ${ }^{1 *}$ \\ ${ }^{1}$ Maritime University of Constanta, Faculty of Naval Electromechanics, 104 Mircea cel Batran Street, \\ 900663, Constanta, România
}

\begin{abstract}
The use of experimental investigation techniques in the research of internal combustion engines has contributed substantially to their progress and development over time. The performances obtained in the development of modern engines have been strongly influenced by the emergence and development of the investigation equipment, especially the laser and the modern computing technique. Maritime transport generates about $4 \%$ of the total $\mathrm{CO} 2$ emissions produced by human activities, which means that its carbon value is almost as large as that of Germany. Emissions from this sector are not yet internationally regulated, but this issue is currently being debated within the IMO and the United Nations Framework Convention on climate change (UNFCCC). Of the strategies to reduce pollutant emissions from ships, identified so far, the technical solutions are the first ones that have been implemented on board. The advantage of using technical solutions onboard ships is the high efficiency of reducing a product or several pollutant products, but the main disadvantage is the high cost of implementing and operating them on board ships.
\end{abstract}

\section{Introduction}

Combustion is defined as the transformation of chemical energy (of oxidizable elements contained in fuel) into thermal energy, materialized by a rapid exothermic oxidation reaction, after which a significant amount of energy is released in the form of heat. [1]

Combustion is studied from two points of view: thermodynamic and kinetic. From a thermodynamic point of view, the combustion process is treated globally, in the sense of evaluating the energy of the reactants and the final products, without considering the kinetic mechanism and the intermediate products of combustion.

The carrier of thermal energy resulting from the combustion process consists of the exhaust gases discharged at a temperature that depends on the nature of the fuel, the perfection of the process how the combustion takes place. [1]

From a kinetic point of view, the combustion process highlights the existence of a mechanism consisting of several stages of process accomplishment and the role of active radicals in propagating the flame front. [2] [3]

\footnotetext{
* Corresponding author: catalinfaitar@yahoo.ro
} 


\section{Formating of pollutant emissions}

The exhaust gases resulting from the combustion of the hydrocarbons in the combustion chambers of the internal combustion engines result in the elimination of oxygen from the atmosphere and the release of some compounds as follows: [5] [6]

- $\mathrm{H}_{2} \mathrm{O}$ and $\mathrm{CO}_{2}$

- hydrocarbon (as: $\mathrm{CH}_{4}, \mathrm{C}_{2} \mathrm{H}_{2}, \mathrm{C}_{2} \mathrm{H}_{6}, \mathrm{C}_{2} \mathrm{H}_{8}, \mathrm{C}_{6} \mathrm{H}_{6}, \mathrm{CH}_{2}, \mathrm{CHO}$ )

- carbon monoxide (CO)

- $\quad$ nitrogen oxides $\left(\mathrm{NO}, \mathrm{NO}_{2}, \mathrm{~N}_{2} \mathrm{O}\right)$

- nitrogen compound $\mathrm{NH}_{3}$ and $\mathrm{HCN}$

- $\quad$ sulfur gas $\left(\mathrm{SO}_{2}, \mathrm{OCS}, \mathrm{CS}_{2}\right)$

- halo-carbonates $\left(\mathrm{CHCl}\right.$ and $\left.\mathrm{CH}_{3} \mathrm{Br}\right)$

- particles of material.

Pollutant emissions can be divided into primary and secondary pollutant emissions. Primary pollutant emissions are those which, following combustion, are emitted directly into the atmosphere. Secondary pollutant emissions, on the other hand, are formed as a result of reactions between primary pollutant emissions and other compounds found in the atmosphere. [4] [5]

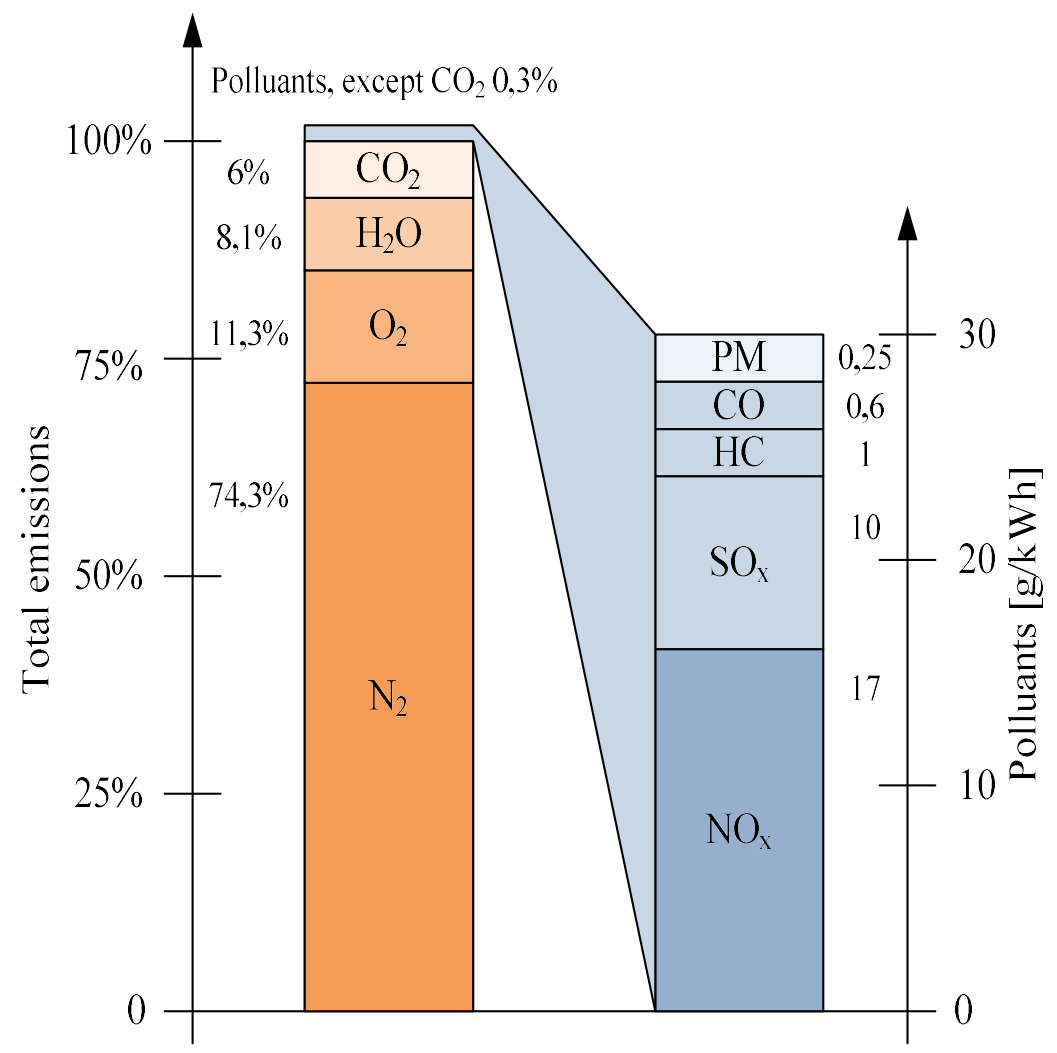

Fig.1. Percentage composition of the exhaust gases of an engine with internal combustion that burns fuel with an average of $3 \%$ Sulfur [7] 


\section{Measurement of the chemical composition of gases}

Chemical gas analyzers are used to determine the chemical composition of the gases. Most of the methods are for the determination of the exhaust gas composition, but some systems allow the analysis of the gases inside the cylinder.

A simple instrument for chemical analysis of flue gases is the Orsat analyzer, which, however, could only measure relatively high concentrations (\%), without being able to measure the concentrations of unburnt hydrocarbons and nitrogen oxides, which are so much needed today. A sample of flue gas is successively passed through a test tube containing potassium hydroxide, which absorbs carbon dioxide, a test tube with pyrogallic acid, which absorbs oxygen, and a test tube containing chlorate, which absorbs carbon oxide.

From these molecular fractions and the hydrogen-carbon ratio of the fuel, respectively the air-fuel ratio, the chemical balance of the flue gases can be determined. The increased attention lately given to pollutant emissions has led to the emergence and use of a new range of chemical analyzers.

These instruments, compared to the classic Orsat analyzer, have a much higher resolution, the routine measurements being made in ppm, compared to the percentages and being able to measure a much wider range of gases, of which, in particular, those required by the regulations in force for polluting emissions.

\subsection{The gas analyzer}

The HORIBA EXSA-1500 gas analyzer is an integrated system for measuring pollutant emissions from engine exhaust gases. The appliance is mounted directly on the exhaust pipe and measures the concentrations of pollutant emissions $\left(\mathrm{CO}, \mathrm{CO}_{2}, \mathrm{NO} / \mathrm{NOx}\right.$ and unburned hydrocarbons) from the undiluted exhaust gases

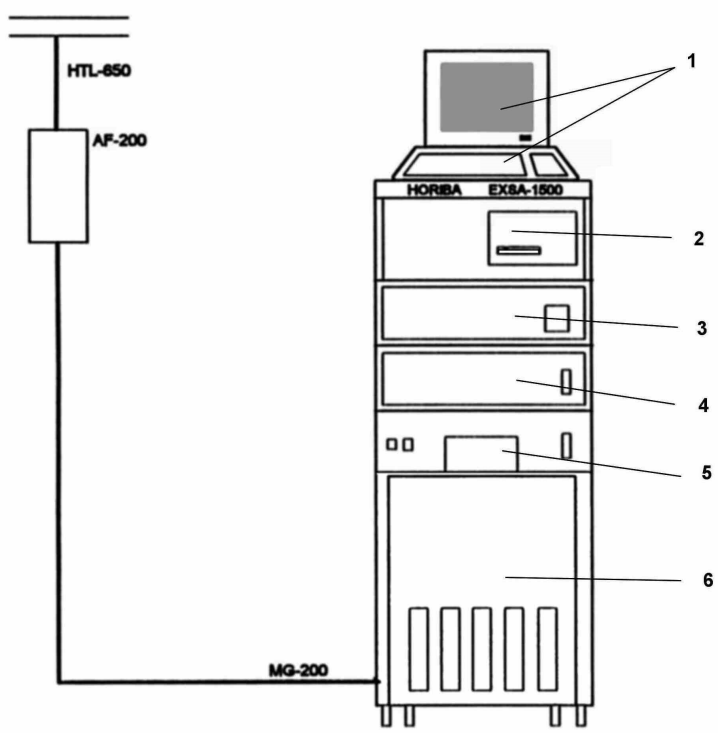

Fig.2. Gas analiser type HORIBA EXAS1500 


\subsection{The operating principles of the measurement subsystems}

The NOX CLA-220UA analyzer is of the chemiluminescence (CLD) type. Chemiluminescence analysis is a precise method of determining the nitrogen oxide content of the exhaust gases, using the luminescence effect characteristic of the reaction between nitrogen monoxide $(\mathrm{NO})$ and ozone $\left(\mathrm{O}_{3}\right)$.

The formed $\mathrm{NO}_{2}$ molecules are partly electronically excited $\mathrm{NO}_{2}$ and relax by emitting photons in the band $0.6 \ldots 3$. Deactivation is also possible by colliding with other inert molecules $\mathrm{M}$, the likely reactions being:

$$
\begin{aligned}
& \mathrm{NO}+\mathrm{O}_{3} \rightarrow \mathrm{NO}_{2}+\mathrm{O} \\
& \mathrm{NO}+\mathrm{O}_{3} \rightarrow \mathrm{NO}_{2}^{*}+\mathrm{O} \\
& \mathrm{NO}_{2}^{*} \rightarrow \mathrm{NO}_{2}+h v \\
& \mathrm{NO}_{2}^{*}+\mathrm{M} \rightarrow \mathrm{NO}_{2}+\mathrm{M}
\end{aligned}
$$

The intensity of the light emitted is proportional to the concentration of $\mathrm{NO}$ and $\mathrm{O}_{3}$, respectively inversely proportional to the concentration of the substance $\mathrm{M}$ :

$$
I=I_{0} \frac{[N O]\left[O_{3}\right]}{[M]} .
$$

In chemiluminescence analyzers, the reaction between $\mathrm{NO}$ and $\mathrm{O}_{3}$ takes place in a continuous flow reactor, at a pressure of $5 \ldots 10$ towers. The light signal is sensed by a photomultiplier tube (figure 3). The presence of $\mathrm{CO}_{2}$ molecules in the gas sample (which plays the role of substance $\mathrm{M}$ in reactions 1) causes the measurement result to be altered depending on the $\mathrm{CO}_{2}$ concentration, by decreasing the signal intensity, a phenomenon known as $\mathrm{CO}_{2}$ interference.

The analyzer used has an error of up to $3 \%$ of the read value if the $\mathrm{CO}_{2}$ concentration is $12 \%$ or less. The analyzer enclosure is thermostated to $450{ }^{\circ} \mathrm{C}$. The ozone required for the reactions is produced in a generator, passing the current of oxygen through an electric arc. The analyzer can also be used to determine the concentration of $\mathrm{NO}_{2}$ in the mixture if $\mathrm{NO}_{2}$ is previously converted to $\mathrm{NO}$, which is done in a converter by thermal dissociation, which uses as Mo-C catalyst. 


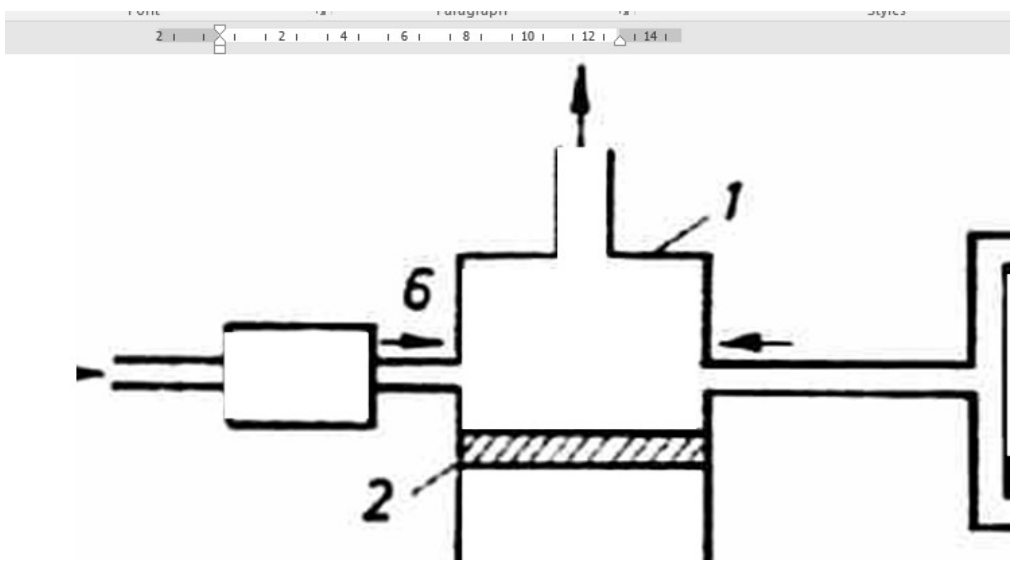

Fig.3. $\mathrm{NO}_{\mathrm{X}}$ analiser 1 reactor; 2-filter; 3-tube photomultiplier; 4- connection with the amplification system; 5 oxygen; 6-ozone generator; 7-NO test; 8 convertorNO $\mathrm{NO}_{2} / \mathrm{NO}$.

\section{Experimental measurement}

To underline the development and implementation of the SEEMP, the situation of a tanker with a capacity of $50000 \mathrm{dwt}$ will be considered (figure 4) [7].

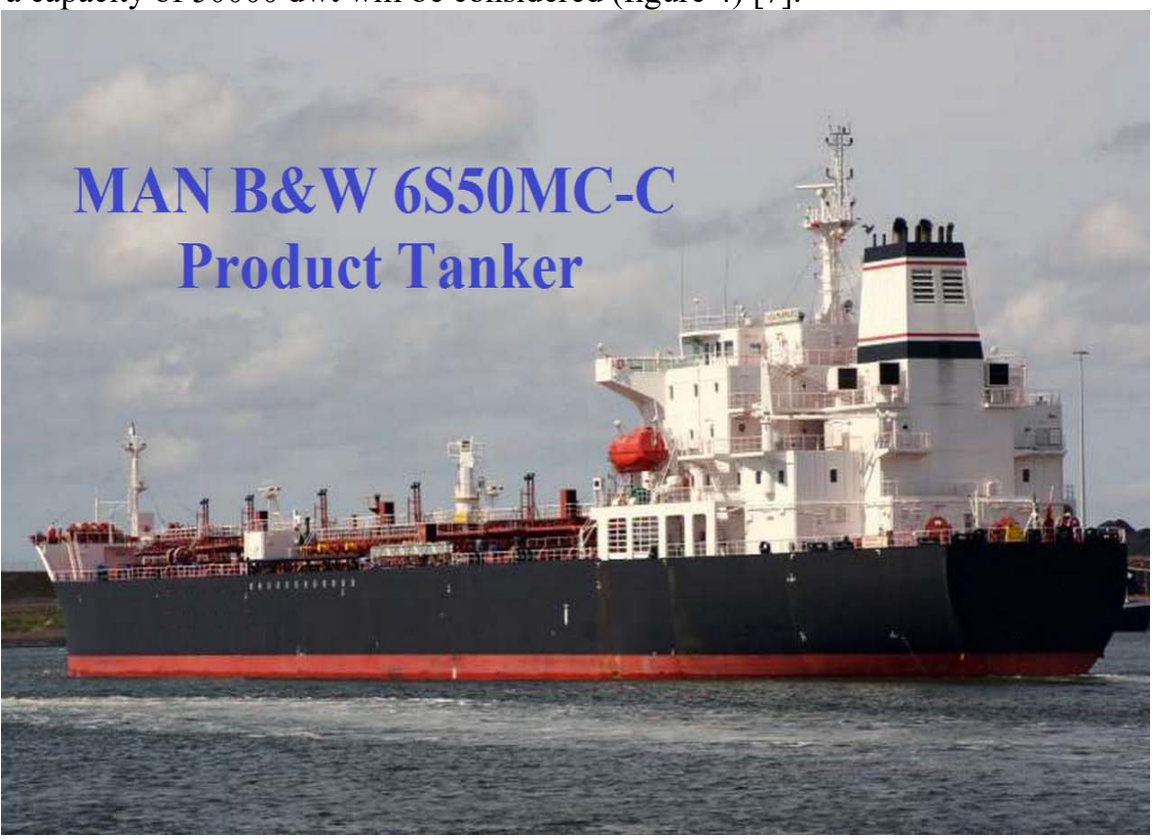

Fig. 4. Reference ship [7]

Ship characteristics:

- $\quad \mathrm{L}_{\mathrm{pp}}=183 \mathrm{~m}$

- $\mathrm{B}=32,2 \mathrm{~m}$

- $\mathrm{V}_{\max }=15,7$ Knots

- $\quad \mathrm{ME}-\mathrm{MAN}$ B\&W 6S50MC-C, P $=8600 \mathrm{~kW}, 127 \mathrm{rpm}$ 
$\mathrm{CO}, \mathrm{CO}_{2}, \mathrm{HC}, \mathrm{NO}_{\mathrm{X}}$ and $\mathrm{SO}_{\mathrm{X}}$ emissions for the main engine and a diesel generator were monitored. The results are presented in Table 1 and Table 2.

Table 1. NOx emissions of the main engine depending on the main engine load

\begin{tabular}{|c|c|c|c|c|c|}
\hline Load [\%] & $\begin{array}{c}\mathrm{NO}_{\mathrm{x}} \\
{[\mathrm{ppm}]}\end{array}$ & $\begin{array}{c}\mathrm{CO} \\
{[\mathrm{ppm}]}\end{array}$ & $\begin{array}{c}\mathrm{SO}_{\mathrm{x}} \\
{[\mathrm{ppm}]}\end{array}$ & $\begin{array}{c}\mathrm{CO}_{2} \\
{[\%]}\end{array}$ & $\begin{array}{c}\mathrm{C} \\
{\left[\mathrm{mg} / \mathrm{m}^{3}\right]}\end{array}$ \\
\hline 100 & 939 & 60 & 63 & 5 & 61 \\
\hline 80 & 722 & 41 & 68 & 4 & 56 \\
\hline 60 & 471 & 21 & 66 & 4 & 51 \\
\hline 40 & 449 & 19 & 40 & 3 & 50 \\
\hline 20 & 571 & 18 & 19 & 1 & 58 \\
\hline
\end{tabular}

Table 2. Generator diesel emissions related to main engine load

\begin{tabular}{|c|c|c|c|c|c|}
\hline Load & $\begin{array}{c}\mathrm{NO}_{\mathrm{x}} \\
{[\mathrm{ppm}]}\end{array}$ & $\begin{array}{c}\mathrm{CO} \\
{[\mathrm{ppm}]}\end{array}$ & $\begin{array}{c}\mathrm{SO}_{\mathrm{x}} \\
{[\mathrm{ppm}]}\end{array}$ & $\begin{array}{c}\mathrm{CO}_{2} \\
{[\%]}\end{array}$ & $\begin{array}{c}\mathrm{C} \\
{\left[\mathrm{mg} / \mathrm{m}^{3}\right]}\end{array}$ \\
\hline 100 & 627 & 178 & 53 & 5 & 32 \\
\hline 80 & 571 & 188 & 50 & 4 & 33 \\
\hline 60 & 638 & 173 & 52 & 5 & 32 \\
\hline 40 & 620 & 177 & 50 & 4 & 32 \\
\hline 20 & 624 & 168 & 51 & $4 \%$ & 32 \\
\hline
\end{tabular}




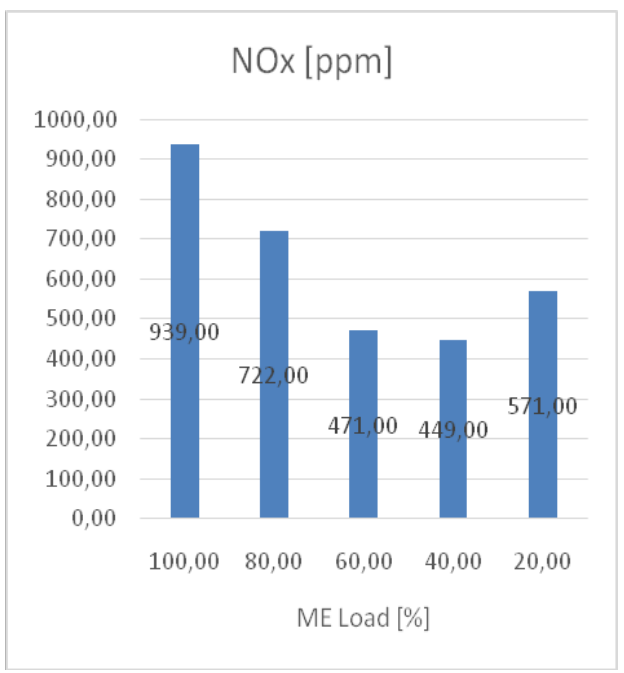

Fig. 5. $\mathrm{NO}_{\mathrm{x}}$ emissions - main engine $[\mathrm{ppm}]$

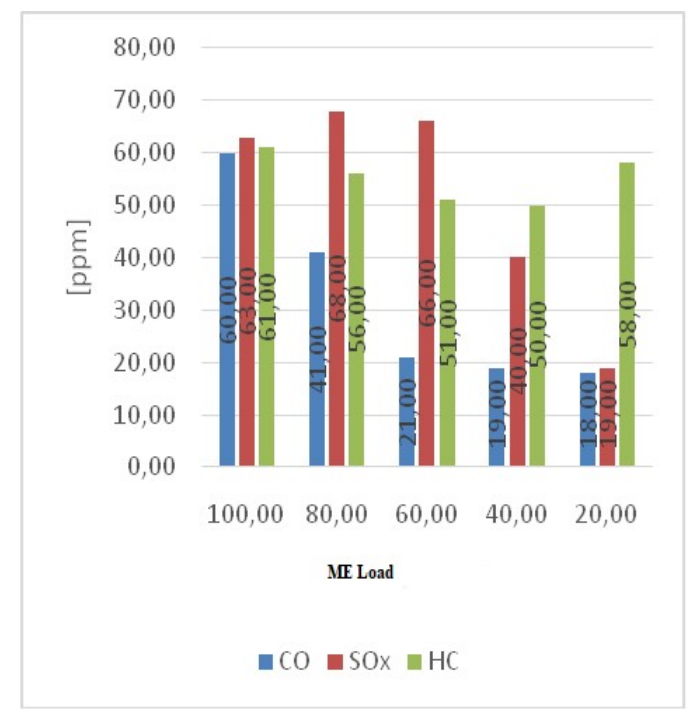

Figure 7. CO, SOx and $\mathrm{HC}$ emissions - main engine [ppm]

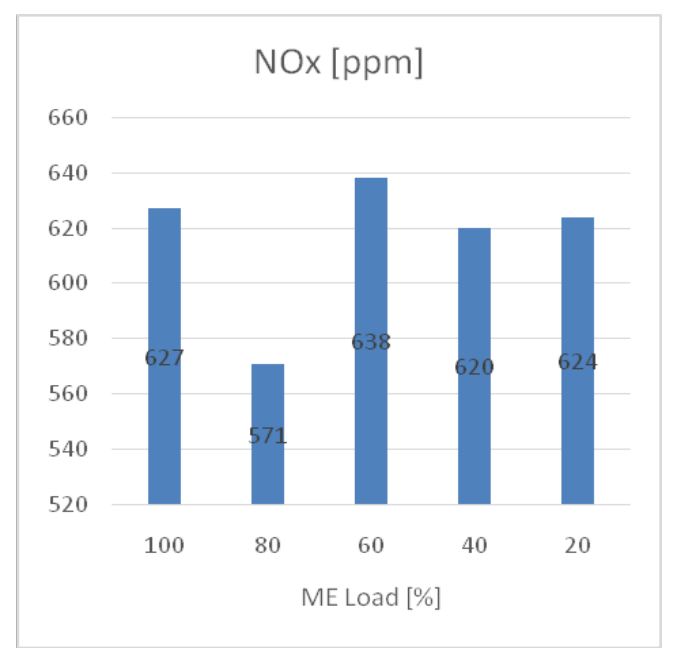

Fig. 6. $\mathrm{NO}_{\mathrm{x}}$ emissions - auxiliary engine [ppm]

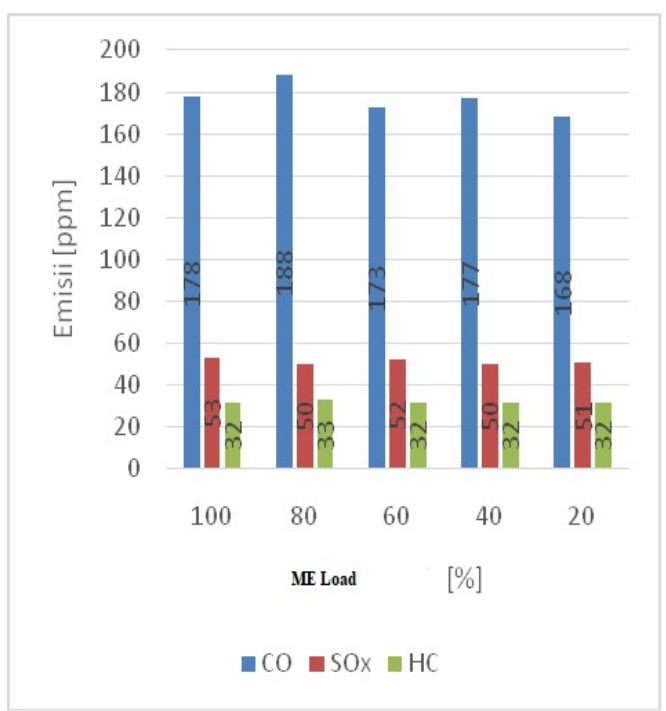

Figure 8. $\mathrm{CO}$, SOx and $\mathrm{HC}$ emissions - auxiliary engine [ppm] 


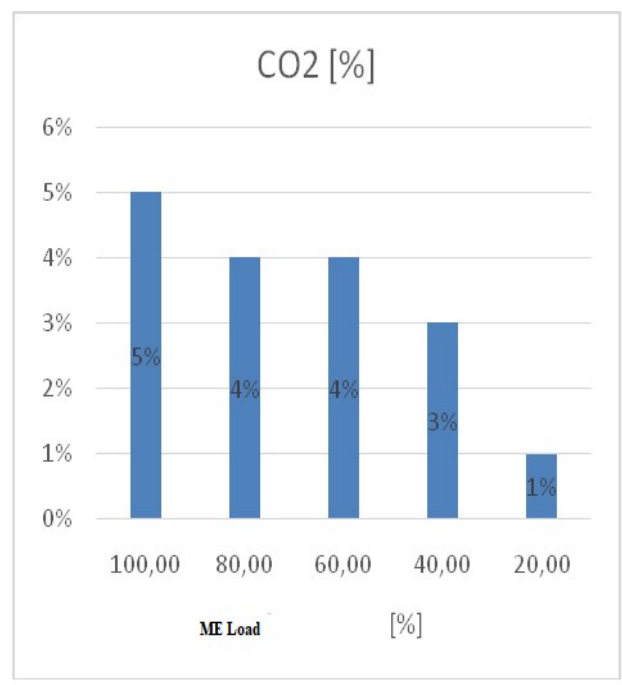

Fig. 9. $\mathrm{CO}_{2}$ emissions - main engine $[\%]$

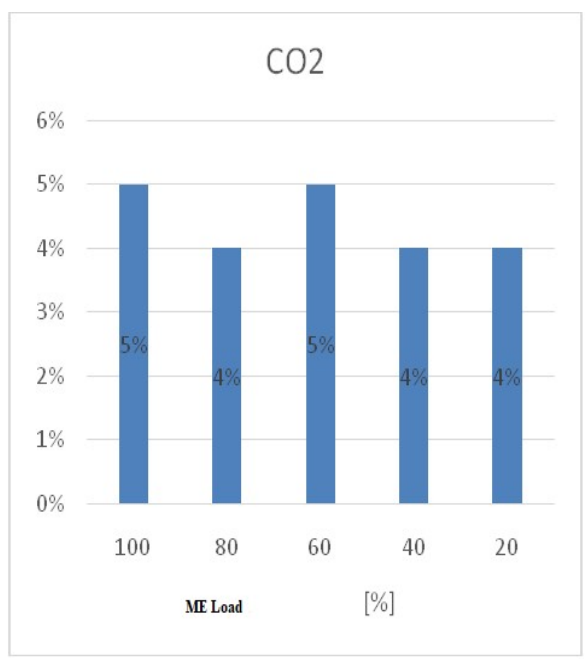

Fig. 10. $\mathrm{CO}_{2}$ emissions - auxiliary engine $[\%]$

Analyzing Figures $5-10$, it is found that, with the reduction of the main engine load, NOx emissions have a decreasing tendency, up to a load of $20 \%$, when an increase of $22 \mathrm{ppm}$ is observed compared to the value recorded for the load of $40 \%$.

The same emission category has a relatively constant variation for the auxiliary engine. As regards $\mathrm{CO}, \mathrm{SO}_{\mathrm{x}}$ and $\mathrm{HC}$ emissions, there is a clear tendency to decrease these categories of pollutants, for the main engine, except for the emissions of unburnt hydrocarbons, which, due to the low coefficient of excess air at low load, show a marked increase.

\section{Conclusions}

For the auxiliary engine, due to the loads induced by the various consumers on board, the emission variation does not follow a trend associated with the variation of the main engine load. However, for short intervals, in the transient range around $40 \%$ of the nominal load, at the moment when the turbocompressor motors serving the main engine at low loads come into operation, there is a temporary increase in the level emissions because of diesel generator running. $\mathrm{CO}_{2}$ emissions are in the same trend as those shown above, with a clear tendency to lower emissions for the main engine, while for the auxiliary engine, emissions vary according to a law independent of the load of the main engine. It is found that by implementing such measures to increase energy efficiency, a reduction in emissions of pollutants and, consequently, a reduction in the consumption of consumed fuel is achieved.

In this way, it can be stated that the operational approach to increase the overall efficiency of the energy system represented by the ship is a viable solution. 


\section{References}

1. European Communities, Council Directive of 7 March 1985 on Air Quality standard for Nitrogen Dioxid (85/203/EEC), Official Journal of the European Communities, No. L87/1, Luxemburg, (1985)

2. Arcadis Belgium nv/sa, Directive European Commission, Contract $N^{\circ}$ 070307/2010/577902/ETU/F1 EC DG Environment Project number 11601, Final report, (2012)

3. D. Bodolan, Metode de control şi reducere a emisiilor poluante ale sistemelor energetic navale, Universitatea Maritimă Constanţa, (2003)

4. http://www.marineinsight.com/news/nichio-maru-the-new-green-car-carrier-fromnissan

5. P. Arsenie, G. Martinas, C. Gheorghe, A. Arsenie A ,Technologies for the Reduction of Nitrogen Oxides Emissions, TRANSNAV, Vol 9 Nr 2, p251-256 (2015)

6. ABS Ship Energy Efficiency Measures Advisory, TX 05/13 500013015

7. Manual de utilizare al simulatorului Transas ERS TechSim, model MAN B\&W 6S50MC-C 